\title{
Gender compatibility, math-gender stereotypes, and self-concepts in math and physics
}

\author{
Ravinder Koul ${ }^{*}$ \\ College of Education, The Pennsylvania State University, 177 Chambers, University Park, \\ Pennsylvania 16802, USA
}

Thanita Lerdpornkulrat

Innovative Learning Center, Srinakharinwirot University, 114 Sukhumvit 23, Bangkok 10110, Thailand

Chanut Poondej

Innovative Learning Center, Srinakharinwirot University, 114 Sukhumvit 23, Bangkok 10110, Thailand

(Received 6 January 2015; published 1 August 2016)

\begin{abstract}
[This paper is part of the Focused Collection on Gender in Physics.] Positive self-assessment of ability in the quantitative domains is considered critical for student participation in science, technology, engineering, and mathematics field studies. The present study investigated associations of gender compatibility (gender typicality and contentedness) and math-gender stereotypes with self-concepts in math and physics. Statistical analysis of survey data was based on a sample of 170 male and female high school science students matched on propensity scores based on age and past GPA scores in math. Results of MANCOVA analyses indicated that the combination of high personal gender compatibility with low endorsement of math-gender stereotypes was associated with low gender differentials in math and physics self-concepts whereas the combination of high personal gender compatibility with high endorsement of math-gender stereotypes was associated with high gender differentials in math and physics self-concepts. These results contribute to the recent theoretical and empirical work on antecedents to the math and physics identities critical to achieving gender equity in STEM fields.
\end{abstract}

DOI: 10.1103/PhysRevPhysEducRes.12.020115

\section{INTRODUCTION}

Equal participation of males and females in study and selection of careers in science, technology, engineering, and mathematics (STEM) fields is considered a critical goal for science education reform efforts worldwide [1-3]. Yet, the potential to achieve this goal remains influenced by differential views of ability and opportunity structures based on sex [4-9]. As a sociocultural phenomenon, gender ideology shapes how individuals define themselves - their notion of self, their cultural beliefs about gender [2,6,10]; it naturalizes perceptions of differences of ability between both the sexes and the gendered nature of knowledge domains.

This paper reports the results of an investigation on the relationship between multiple measures of gender identity and self-concepts in math and physics among males and females enrolled in the same science-math academic stream in Thailand and matched in terms of their past school performance in math.

\footnotetext{
Corresponding author. RXK141@PSU.EDU

Published by the American Physical Society under the terms of the Creative Commons Attribution 3.0 License. Further distribution of this work must maintain attribution to the author(s) and the published article's title, journal citation, and DOI.
}

\section{BACKGROUND}

In the literature on math and science education, inequity between the sexes has classically been defined in terms of lower female enrollment in secondary level advanced math and science courses and lower female enrollment and retention in physical science programs in colleges [11]. In Thailand, where we conducted the study reported in this paper, almost equal proportions of males and females are enrolled in science-math academic streams at the upper secondary school level and females are well represented in math and science undergraduate programs in Thai colleges and universities. In the year 2013, the top eleven Thai universities reported that the proportion of females enrolled in undergraduate degree programs in biology, chemistry, math, physics, and computer sciences were $76.47 \%, 73.97 \%, 63.38 \%, 52.87 \%$, and $45.81 \%$, respectively [12]. Yet, Thai females are less than half as likely as Thai males to be employed in science and technology jobs and continue to be underrepresented in high earning careers in STEM fields $[3,13]$.

Gender identity is considered one of the most pervasive and enduring influences on personal goals, aspirations, and behavior [14]. It is for this reason that a growing body of literature emphasizes the centrality of gender identity to the promotion of equity in science education [2,15-17]. Gender identity is often defined in terms of feminine or 
masculine sex-role identity. Feminine or masculine sex-role identity emerges from an evaluation of one's self as having more traits regarded as stereotypically feminine or masculine. Aspects of gender identity include feelings of psychological compatibility with one's gender (i.e., feeling one is a typical member of one's sex and feeling content with one's biological sex), feelings of pressure from parents, peers, and self to conform to gender stereotypes [18]. The power of the social significance of gender motivates students to learn about and comply with gender norms [19]. The social significance of gender extends to perceptions of the nature of knowledge domains. For example, physics is perceived as a highly masculine domain while math may be perceived as somewhat masculine or gender neutral [3,11], although math and physics are often treated interchangeably in research studies.

Math and physics are considered essential subjects in preparation for high earning careers in STEM fields [3,11,20-22]. Many social theorists agree that lack of parity for the sexes can be best understood through an examination of self-concept because of its predictive power to explain sex differences related to interest, persistence, coursework selection, and academic achievement [23-25]. Self-concept is described as domain-specific perceptions of self-competence, formed through interactions and experiences in the environment [26]. Math self-concept has been found to be strongly associated with learning gains for students and achievement-related choices [27,28]. Perceptions of self-competence in both math and physics become more significant during secondary school when students settle into academic paths or make career decisions [11,29-32].

Carlone [33] concludes that adolescent females may try to avoid science activities that are incongruent with their gender identities. Brickhouse and Potter [2] conclude that females may find it hard to negotiate the culture of school science when their school science identity is inconsistent with their gender identity. Baker [34] concludes that females who aspire to science related careers perceive themselves as more masculine while females who aspire to careers traditionally deemed suitable for women perceive themselves as more feminine. Baker [34] suggests that selfevaluation as typically female or satisfaction with female gender identity should therefore negatively associate with identification with science. Gilbert and Calvert [35] conclude that females who are attracted to science are attracted to aspects of science typically associated with masculinity and men. Addressing the inclination of science attraction by looking specifically on the male-typed domain of physics, Murphy and Whitelegg [30] suggested that females won't feel they "belong" in physics if identification with physics may be seen as "a gender transgressive act which challenges a key signifier of femininity" [11,31]. This clarifies Danielsson's [36] assertion that doing physics is "doing gender," that for a female student to adopt a physics identity requires her to distance herself from what is traditionally female. So, do the findings of prior research mean that "femininity" is harmful to girls in subjects such as math and physics? Are self-concepts in math and physics negatively affected by positive identification with female gender assignment?

The demographic category of sex is often used to assess gender differences in perceptions of competence in math and science. "Sex refers to the biological features that make one a male or a female whereas gender refers to a set of traits, behaviors, and expectations that cultures train girls and boys to practice and hold, usually described as those that are feminine and those that are masculine" $[15,37]$. Gender identity may be described as knowledge of one's membership in a sex-typed group [38]. Gender identity is a core element in the development of sense of self [39]. In Egan and Perry's [18] multidimensional model, gender identity reflects the collection of thoughts and feelings one has for one's gender category or "felt gender compatibility," which means degree of gender typicality, and "gender contentedness," the degree of happiness with one's gender category.

The idea of male or female roles evokes preferences based on gender [40]. When such preferences are referred to as characteristics that males and females are likely to possess and should possess, they are called cultural beliefs about gender or gender stereotypes [21,41] which "function as cultural schemas for interpreting and making sense of the world" [6,42]. Common gender stereotypes include the association of math and physics with males and language and humanities with females.

Perry and Pauletti [9] view personal identity-plusstereotype patterns as causal systems that influence an adolescent's efforts to develop and regulate the self. Past research has found that self-evaluations in math are likely to be influenced by how well an individual's behaviors and sex roles conform to stereotypes associated with persons of the same gender [6,9,17,43-45]. Nosek et al. [44] and Cvencek et al. [17] found that girls' weaker identification with math or their low self-concept in math may derive from strong gender identity and cultural beliefs that math is more appropriate for males than for females. Whether males and females attend equally to male-advantage beliefs is unclear [46]. It is unclear whether females with high gender typicality and contentedness have lower selfconcept in domains stereotyped as masculine. Does the relationship between personal identity-plus-stereotype patterns and self-concept differ across subject domains? Differences between students' self-evaluations in math and physics have not previously been examined.

This study presents results of an investigation on associations of a combination of felt gender compatibility and math-gender stereotypes with self-concepts in math and physics among a sample of Thai secondary school students. Results of this investigation contribute to the 
knowledge regarding the antecedents to gender differentials in self-concepts in math and physics.

\section{THEORETICAL FRAMEWORK AND HYPOTHESES DEVELOPMENT}

The theoretical framework for our study is grounded in the social psychology theories of self-efficacy $[19,47]$, expectancy value $[7,48,49]$, and cognitive balance $[50,51]$. Self-efficacy theory posits that social processes such as internalization of gender roles have an important influence on the development of self-efficacy and academic choices [52]. Children internalize social sanctions against gender inappropriate behaviors and develop sex-typed notions of self-efficacy. They learn to believe themselves less competent in gender inappropriate domains [19,53]. For example, when children find few women scientists and engineers, they tend to have low expectations for women to be successful in these fields [19], and according to expectancy-value theory, such gender role schemas predict gender differences in expectations for success and value assigned to different school subjects [7]. Cognitive balance theory suggests that stereotypical attitudes, social identity, and self-concept are organized into cognitive structures that are mutually consistent or balanced [17,50,51]. This tendency (what social psychologists call cognitive balance) is illustrated in the following combination [17]: Cultural stereotypes ("math is for males") with the knowledge about one's gender identity ("I am female") is likely to be associated with an individual's self-concept in math ("math is not for me"). Figure 1 presents the framework used in this study to assess the relationship between measures of gender identity and math and physics identities.

Studies have reported a relationship between gender identity and self-evaluation [3,6,46,54-56]. Correll [6,46] found that integration of math-gender stereotypes that favor males has positive association with math self-concept for males and negative association with math self-concept for females. By the same token, Leaper and Van [56] found that gender typicality was negatively associated with selfevaluation in gender inappropriate fields. Research has also shown that endorsement of math-gender stereotypes benefits males more than females [3,57]. In our study, we hypothesized that males who affirm high felt gender compatibility (gender typicality and gender contentedness) would report higher levels of self-concept in math and physics than males who affirm low felt gender compatibility. We also hypothesized that males who endorse higher levels of math-gender stereotypes would report higher levels of self-concept in math and physics than males who endorse low levels of math-gender stereotypes. Consistent with prior empirical evidence $[6,44,46]$, we hypothesize that the relationship between our measures of gender identityplus-stereotypes patterns and self-concept in math and physics would likely differ for males and females.

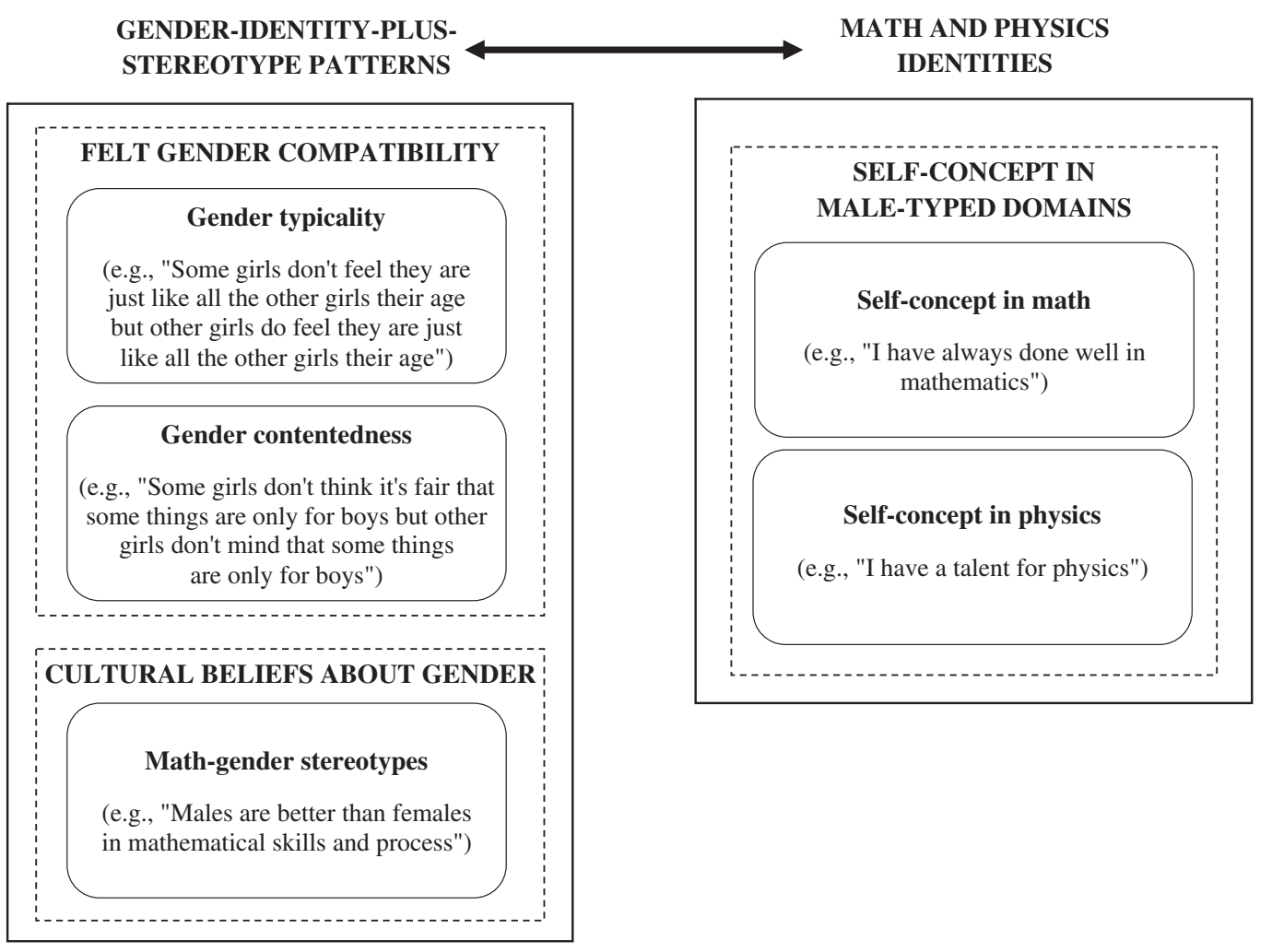

FIG. 1. Conceptual framework for the study. 


\section{METHODOLOGY}

\section{A. Participants}

The educational system in Thailand provides six years of primary education (called Prathom), followed by three years of lower secondary education (called Mathayom 1, 2, and 3), and three years of upper secondary education (called Mathayom 4, 5, and 6). When students transition from the lower secondary to the upper secondary level of education, they are tracked into an academic or vocational stream. Biology, chemistry, and physics are compulsory subjects for students in the science-math academic stream. We collected survey data from every student enrolled in the science-math stream in three different schools located in the same community in central Thailand. All participants in our January 2013 survey were taking the same math and physics courses under the Thai national curriculum. There are equal proportions of males and females enrolled in science-math academic streams in Thailand, however, the majority of students in our survey were females because these schools are in transition from same-sex to coed education. Our response rate of $94.0 \%$ for both males and females was based on complete surveys only $(N=550, \quad$ Males $=16.0 \%$; Females $=84.0 \%)$. Respondents were 14-19 years old $(M=16.67, \mathrm{SD}=0.98), 34.0 \%$ of the students were enrolled in 10th grade (Mathayom 4), 34.4\% in 11th grade (Mathayom 5), and $31.6 \%$ in 12th grade (Mathayom 6).

\section{B. Measures}

Our survey questionnaire was written in Thai and divided into two sections. The first part of the survey asked for general information, which included gender, age, and GPA. The second part of the survey assessed gender typicality, gender contentedness, endorsement of math gender stereotypes, and self-concepts in math and physics. Our survey questions were developed for the Thai context using the standard research technique of translation and back-translation [58]. Questions were initially developed in English by the principal researcher. Two bilingual Thai researchers then translated each item into Thai. Two bilingual researchers and the principal researcher reviewed each item written in Thai and translated it back into English. Finally, the English and Thai translations were compared, and, by consensus, found to be conceptually equivalent.

Measures of self-concepts were based on instruments developed and validated by Marsh [59] and Pietsch, Walker, and Chapman [60]. The twelve items in our survey were designed to measure self-concept in math and physics, using the 5-point Likert scale ranging from 1 (strongly disagree) to 5 (strongly agree) (sample items: "I have always done well in mathematics," "I have a talent for physics"). The gender stereotypes measure (6 items) assessed student endorsement of gender stereotypes pertaining to specific math content (sample items: "How would you compare males and females in geometry?", "How would you compare males and females in mathematical skills and processes?") and was validated in a prior study [3]. Responses to these items were made by choosing one of the three options, (a) males are better, (b) females are better, or (c) both males and females are equally good.

The felt gender compatibility measure (12 items) was based on the multidimensional measure of gender identity developed and validated by Egan and Perry [18]. The Thai translations in our questionnaire were designed to measure gender typicality (6 items) (sample item: "Some girls don't feel they're just like all the other girls their age ("very true for me", "sort of true for me") but other girls do feel they're just like all the other girls their age ("sort of true for me", "very true for me")" and gender contentedness (6 items) (sample item: "Some girls like being a girl ("very true for me", "sort of true for me") but other girls don't like being a girl ("sort of true for me", "very true for me")". The gender typicality scale was designed to assess the degree to which students think that their interests, personalities, and competencies are typical of their sex whereas the gender contentedness scale measures the extent to which the students are happy with their gender assignment and rarely wish to participate in cross-sex activities. The internal consistency of the scales measuring gender typicality, gender contentedness, and math-gender stereotypes was good ( $\alpha=0.68$ for gender typicality scale, $\alpha=0.73$ for gender contentedness scale, and $\alpha=0.85$ for math-gender stereotypes scale).

\section{ANALYSIS}

\section{A. Confirmatory factor analysis}

We performed confirmatory factors analysis to determine if math self-concept and physics self-concept represent two empirically distinct constructs. Results using one factor model (all items are deemed to measure perceived math and physics-related competence) indicated a poor fit, $\chi^{2}=1527.77, p=0.000, \chi^{2} / d f=56.58, \mathrm{CFI}=0.638$, $\mathrm{GFI}=0.626, \mathrm{NFI}=0.634, \mathrm{SRMR}=0.182, \mathrm{RMSEA}=$ 0.284 . RMSEA and SRMR values $<0.05$ are considered to indicate a good fit. The fit of the two-factor model was quite good: $\chi^{2}, 132.91, p=0.000, \chi^{2} / d f=5.11, \mathrm{CFI}=$ $0.974, \quad$ GFI $=0.958, \quad$ NFI $=0.968, \quad$ SRMR $=0.031$, RMSEA $=0.077$. In our two-factor model, all factor loadings were greater than 0.66 , no cross loadings were observed, and the internal consistency of both scales was good $(\alpha=0.91$ for math self-concept and 0.89 for physics self-concept). These results indicate that self-concept in math and self-concept in physics represent interrelated but distinct judgments of perceived self-competence. 


\section{B. Sample selection using propensity scoring approach}

In order to address the measurement bias in sample selection, we used the propensity score blocking technique [61] to model the selection of students into equal numbers of males and females. Prior research has linked self-concept in math with age and math GPA scores $[62,63]$. We therefore controlled for age and math GPA scores as covariates. A logit model with gender grouping as the outcome variable and the covariates as predictors was estimated. Based on the predicted probabilities, a nearest neighbor matching algorithm matched males with females based on similar probabilities with respect to age and GPA scores in math (optimal 1:1 matching method was used). In our final sample of an equal number of males $(n=85)$ and females $(n=85)$, the covariates (age and GPA scores in math) were "balanced," which means that there were no statistically significant gender differences in the means of these covariates. Since prior research findings suggest that motivational considerations involved in math and science fields substantially differ according to gender $[64,65]$, we conducted separate MANCOVA analyses for males and females.

\section{RESULTS}

The GPA in math was significantly $(p<0.01)$ and positively related to self-concept in math for both males and females. The GPA in physics was significantly $(p<0.01)$ and positively related to self-concept in physics for males but not for females. Despite nonsignificant gender differences in math GPA, males reported significantly higher self-concepts in both math and physics than the females $\left(F=19.90, p<0.01\right.$, partial $\eta^{2}=0.110$ and $F=35.86, p<0.01$, partial $\eta^{2}=0.176$, respectively) (see Table I). Based on Cohen's guidelines [66], the effect size was moderate.

We examined the combined effects of our measures of gender identity and math-gender stereotypes on selfconcepts in math and physics using median-split methodology to classify students into high-to-low gender typicality (median $=2.67, \mathrm{SD}=0.56$ ), high-to-low gender contentedness $($ median $=2.33, \mathrm{SD}=0.61)$ and high-tolow math-gender stereotypes $($ median $=1.00, \mathrm{SD}=1.64$ ) groupings. The median split resulted in the classification of a relatively higher proportion of males than females into high gender typicality (males $=49$ and females $=35$ ), high gender contentedness (males $=71$ and females $=21$ ), and high math-gender stereotypes group (males $=56$ and females $=54$ ). Table II presents mean and standard deviation values for math and physics self-concept as a function of levels of felt gender compatibility and the endorsement of stereotypes.

Separate MANCOVA analyses were conducted for males and females to assess if there were differences between groups based on levels of gender typicality, gender contentedness, and math-gender stereotype on a linear combination of math and physics self-concepts. The assumptions of independence of observations and homogeneity of variance or covariance were checked and met. Bivariate scatterplots were checked for multivariate normality. Box's test of equality of covariance matrices and Levene's test of equality of error variances were nonsignificant for both males and females.

After controlling for the effects of age and prior GPA scores in math and physics, the MANCOVA analysis revealed a positive main effect of gender contentedness on math self-concept for the males only, $F(1,84)=4.77$, $p<0.05$, partial $\eta^{2}=0.061$. There were significant threeway interactions between gender typicality, gender contentedness, and stereotypes on self-concept for the females but not for males (Table III). Using the commonly used guidelines proposed by Cohen [66] $(0.01=$ small, $0.06=$ moderate, and $0.14=$ large effect), the results suggest moderate effect size for three-way interactions between gender typicality, gender contentedness, and mathgender stereotypes on self-concept in math and physics for females (see Table III and Fig. 2). Among females who endorsed low levels of math-gender stereotypes or affirmed

TABLE I. Means, standard deviations (SD), and correlations between study variables $(n=170)$.

\begin{tabular}{|c|c|c|c|c|c|c|c|c|c|c|c|c|}
\hline \multirow[b]{2}{*}{ Variable } & \multicolumn{2}{|c|}{ Males $(n=85)$} & \multicolumn{2}{|c|}{ Females $(n=85)$} & \multicolumn{8}{|c|}{ Intercorrelations } \\
\hline & Mean & SD & Mean & SD & 1 & 2 & 3 & 4 & 5 & 6 & 7 & 8 \\
\hline 1. Age (14-19 years) & 16.54 & 1.05 & 16.45 & 0.97 & $\cdots$ & 0.02 & $-0.35^{* *}$ & 0.01 & -0.09 & 0.12 & -0.21 & -0.17 \\
\hline 2. Math GPA $(1-4)$ & 3.41 & 0.82 & 3.43 & 0.65 & -0.09 & $\ldots$ & $0.72^{* *}$ & 0.01 & 0.11 & 0.15 & $0.52^{* *}$ & -0.12 \\
\hline 3. Physics GPA (1-4) & 2.56 & 0.99 & 2.09 & 0.64 & -0.07 & $0.50^{* *}$ & $\cdots$ & 0.04 & 0.12 & 0.10 & $0.52^{* *}$ & 0.02 \\
\hline 4. Gender typicality (1-4) & 2.83 & 0.54 & 2.65 & 0.48 & 0.17 & 0.20 & $0.22^{*}$ & $\cdots$ & $0.32^{* *}$ & 0.10 & 0.06 & 0.09 \\
\hline 5. Gender contentedness (1-4) & 2.84 & 0.53 & 1.93 & 0.54 & 0.06 & 0.10 & 0.10 & $0.35^{* *}$ & $\ldots$ & -0.11 & 0.17 & $0.23^{*}$ \\
\hline 6. Gender stereotypes $(0-6)$ & 2.46 & 2.34 & 1.44 & 1.49 & -0.01 & $0.25^{*}$ & 0.10 & $0.22^{*}$ & 0.01 & $\ldots$ & 0.03 & -0.08 \\
\hline 7. Math self-concept (1-7) & 4.89 & 1.23 & 4.12 & 1.00 & -0.14 & $0.47^{* *}$ & 0.16 & -0.07 & 0.14 & $0.28^{*}$ & $\ldots$ & 0.19 \\
\hline 8. Physics self-concept $(1-7)$ & 4.24 & 1.32 & 3.15 & 1.04 & -0.08 & 0.01 & $0.30^{* *}$ & 0.13 & 0.08 & $0.28^{*}$ & $0.25^{*}$ & $\cdots$ \\
\hline
\end{tabular}


TABLE II. Math and physics self-concepts as a function of felt gender typicality and contentedness and level of endorsement of mathgender stereotypes.

\begin{tabular}{|c|c|c|c|c|c|c|c|c|}
\hline & \multicolumn{4}{|c|}{ Math self-concept } & \multicolumn{4}{|c|}{ Physics self-concept } \\
\hline & \multicolumn{2}{|c|}{ Males } & \multicolumn{2}{|c|}{ Females } & \multicolumn{2}{|c|}{ Males } & \multicolumn{2}{|c|}{ Females } \\
\hline & Mean & $\mathrm{SD}$ & Mean & $\mathrm{SD}$ & Mean & $\mathrm{SD}$ & Mean & SD \\
\hline \multicolumn{9}{|c|}{ Gender typicality } \\
\hline Low & 5.15 & 1.10 & 4.11 & 1.11 & 4.15 & 1.44 & 3.02 & 1.06 \\
\hline High & 4.70 & 1.29 & 4.15 & 0.85 & 4.31 & 1.24 & 3.33 & 1.01 \\
\hline \multicolumn{9}{|c|}{ Gender contentedness } \\
\hline Low & 4.01 & 1.12 & 4.00 & 1.03 & 3.90 & 1.27 & 2.98 & 0.91 \\
\hline High & 5.06 & 1.18 & 4.36 & 0.93 & 4.31 & 1.33 & 3.46 & 1.21 \\
\hline \multicolumn{9}{|c|}{ Gender stereotypes } \\
\hline Low & 4.52 & 1.06 & 4.15 & 1.09 & 3.87 & 1.28 & 3.26 & 1.28 \\
\hline High & 5.08 & 1.27 & 4.11 & 0.96 & 4.43 & 1.32 & 3.08 & 0.88 \\
\hline
\end{tabular}

what we refer to as egalitarian attitudes toward math, a combination of high gender typicality and high gender contentedness had positive associations with self-concept in math and physics. Among females who highly endorsed math-gender stereotypes or affirmed what we refer to as traditional stereotypical attitudes toward math, a combination of high gender typicality and high gender contentedness was negatively associated with self-concept in math and physics (Fig. 2). Table III presents the results of
MANCOVA analyses and Fig. 2 presents three-way interactions for females. The results of MANCOVA analyses allowed us to compute estimated marginal mean values on math and physics self-concepts for the male and female groups, which were found to vary with different combinations of high and low scores on gender typicality, gender contentedness, and math-gender stereotypes (see Table IV). The gender differentials in estimated means values on math and physics self-concepts were low among students with

TABLE III. MANCOVA analyses: Univariate effects of gender compatibility and math-gender stereotypes on math and physics selfconcepts (age and math and physics GPA scores are covariates) $(n=170)$.

\begin{tabular}{|c|c|c|c|c|c|c|c|c|}
\hline \multirow[b]{2}{*}{ Source } & \multirow[b]{2}{*}{ Dependent variable } & \multirow[b]{2}{*}{$d f$} & \multicolumn{3}{|c|}{ Males } & \multicolumn{3}{|c|}{ Females } \\
\hline & & & $F$ & $p$ & $\eta^{2}$ & $F$ & $p$ & $\eta^{2}$ \\
\hline \multirow[t]{2}{*}{ Age } & Math self-concept & 1 & 0.32 & 0.577 & 0.004 & 1.85 & 0.178 & 0.024 \\
\hline & Physics self-concept & 1 & 0.20 & 0.658 & 0.003 & 0.48 & 0.492 & 0.006 \\
\hline \multirow[t]{2}{*}{ Math GPA } & Math self-concept & 1 & 14.40 & $0.000^{* *}$ & 0.163 & 8.98 & $0.004^{* *}$ & 0.108 \\
\hline & Physics self-concept & 1 & 5.63 & $0.020^{*}$ & 0.071 & 1.01 & 0.319 & 0.013 \\
\hline \multirow[t]{2}{*}{ Physics GPA } & Math self-concept & 1 & 0.17 & 0.686 & 0.002 & 1.34 & 0.251 & 0.018 \\
\hline & Physics self-concept & 1 & 12.44 & $0.001^{* *}$ & 0.144 & 0.16 & 0.693 & 0.002 \\
\hline \multirow[t]{2}{*}{ Typicality } & Math self-concept & 1 & 2.62 & 0.110 & 0.034 & 1.13 & 0.292 & 0.015 \\
\hline & Physics self-concept & 1 & 0.04 & 0.842 & 0.001 & 0.01 & 0.941 & 0.000 \\
\hline \multirow[t]{2}{*}{ Contentedness } & Math self-concept & 1 & 4.77 & $0.032^{*}$ & 0.061 & 2.16 & 0.146 & 0.028 \\
\hline & Physics self-concept & 1 & 2.11 & 0.151 & 0.028 & 3.55 & 0.064 & 0.046 \\
\hline \multirow[t]{2}{*}{ Stereotypes } & Math self-concept & 1 & 0.30 & 0.589 & 0.004 & 0.05 & 0.831 & 0.001 \\
\hline & Physics self-concept & 1 & 3.66 & 0.060 & 0.047 & 0.16 & 0.690 & 0.002 \\
\hline \multirow[t]{2}{*}{ Typicality $x$ contentedness } & Math self-concept & 1 & 0.00 & 0.961 & 0.000 & 0.23 & 0.637 & 0.003 \\
\hline & Physics self-concept & 1 & 0.17 & 0.685 & 0.002 & 0.44 & 0.508 & 0.006 \\
\hline \multirow[t]{2}{*}{ Typicality $x$ stereotypes } & Math self-concept & 1 & 0.60 & 0.442 & 0.008 & 0.95 & 0.334 & 0.013 \\
\hline & Physics self-concept & 1 & 0.18 & 0.671 & 0.002 & 0.05 & 0.826 & 0.001 \\
\hline \multirow[t]{2}{*}{ Contentedness $x$ stereotypes } & Math self-concept & 1 & 0.36 & 0.548 & 0.005 & 2.40 & 0.125 & 0.031 \\
\hline & Physics self-concept & 1 & 0.30 & 0.586 & 0.004 & 0.29 & 0.593 & 0.004 \\
\hline \multirow{2}{*}{ Typicality $x$ contentedness $x$ stereotypes } & Math self-concept & 1 & 1.83 & 0.180 & 0.024 & 7.22 & $0.009^{* *}$ & 0.089 \\
\hline & Physics self-concept & 1 & 0.06 & 0.809 & 0.001 & 8.56 & $0.005^{* *}$ & 0.104 \\
\hline
\end{tabular}

$$
\begin{aligned}
& { }^{*} p<0.05 . \\
& { }^{*} p<0.01 .
\end{aligned}
$$

Note. For males, adjusted $R^{2}=0.319$ for math self-concept and 0.100 for physics self-concept. For females, adjusted $R^{2}=0.366$ for math self-concept and 0.098 for physics self-concept. 
(a) Low math-gender stereotypes

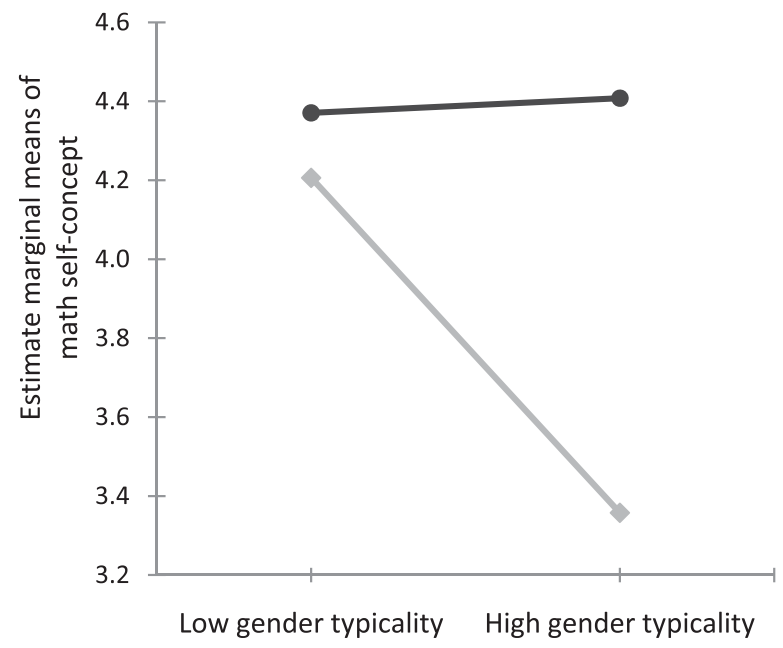

(c) Low math-gender stereotypes

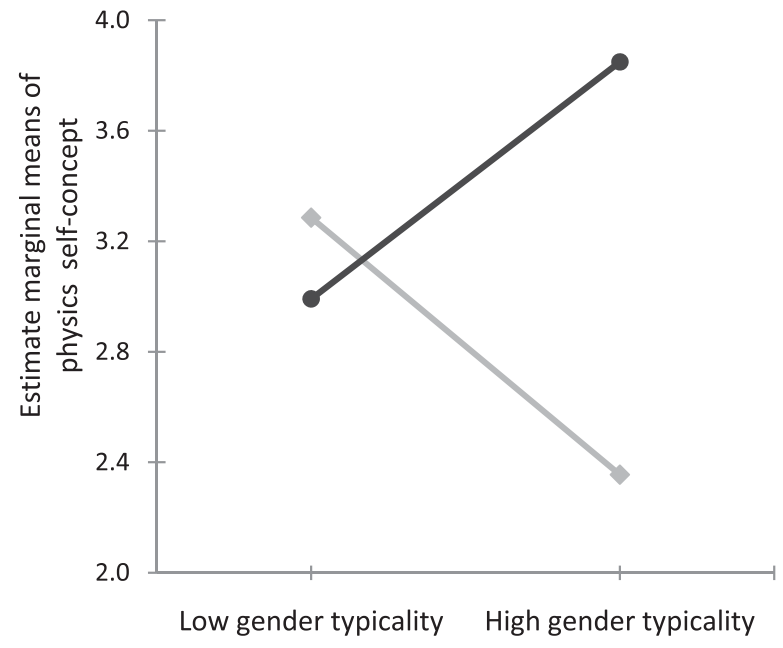

(b) High math-gender stereotypes

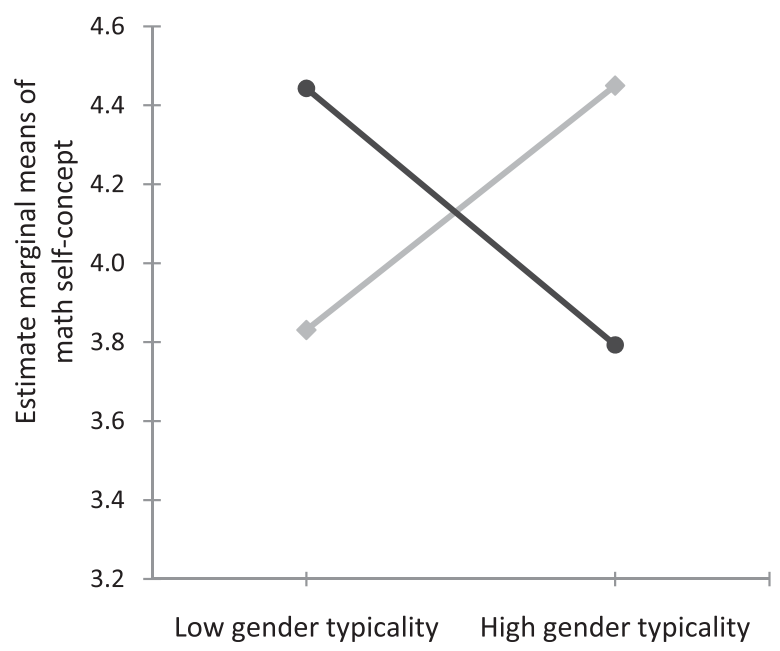

(d) High math-gender stereotypes

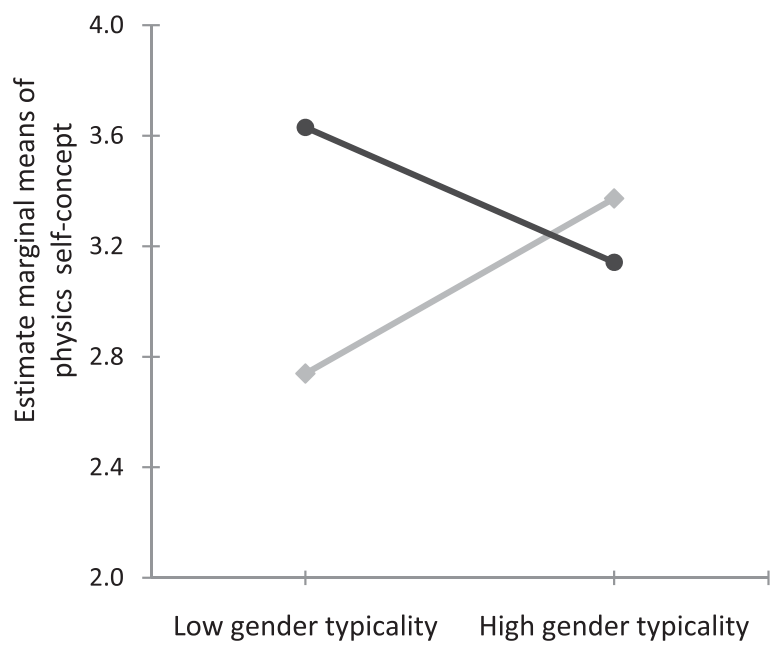

$\longrightarrow$ High gender contentedness

FIG. 2. Three-way interactions between felt gender typicality, gender contentedness, and math-gender stereotypes on math selfconcept $(\mathrm{a}, \mathrm{b})$ and on physics self-concept $(\mathrm{c}, \mathrm{d})$ for females (age and GPA scores in math and physics are control variables).

TABLE IV. Gender differentials in math and physics self-concepts based on MANCOVA analyses.

\begin{tabular}{|c|c|c|c|c|c|c|c|c|}
\hline \multirow[b]{2}{*}{$\begin{array}{l}\text { Level of endorsement } \\
\text { of math-gender stereotypes }\end{array}$} & \multirow[b]{2}{*}{$\begin{array}{l}\text { Gender } \\
\text { typicality }\end{array}$} & \multirow[b]{2}{*}{$\begin{array}{c}\text { Gender } \\
\text { contentedness }\end{array}$} & \multicolumn{3}{|c|}{$\begin{array}{c}\text { Math self-concept: } \\
\text { Estimated mean values }\end{array}$} & \multicolumn{3}{|c|}{$\begin{array}{l}\text { Physics self-concept: } \\
\text { Estimated mean values }\end{array}$} \\
\hline & & & Males & Females & $\begin{array}{c}\text { Gender } \\
\text { differentials }\end{array}$ & Males & Females & $\begin{array}{c}\text { Gender } \\
\text { differentials }\end{array}$ \\
\hline \multirow[t]{4}{*}{ Low } & \multirow[t]{2}{*}{ Low } & Low & 4.13 & 4.21 & 0.08 & 3.09 & 2.35 & -0.74 \\
\hline & & High & 5.19 & 4.37 & -0.82 & 3.71 & 2.99 & -0.72 \\
\hline & \multirow[t]{2}{*}{ High } & Low & 4.29 & 3.36 & -0.93 & 2.89 & 3.29 & 0.40 \\
\hline & & High & 4.41 & 4.41 & 0.00 & 4.11 & 3.89 & -0.22 \\
\hline \multirow[t]{4}{*}{ High } & \multirow[t]{2}{*}{ Low } & Low & 4.89 & 3.83 & -1.06 & 4.32 & 2.74 & -1.58 \\
\hline & & High & 5.42 & 4.44 & -0.98 & 4.67 & 3.63 & -1.04 \\
\hline & \multirow[t]{2}{*}{ High } & Low & 3.50 & 4.45 & 0.95 & 3.96 & 3.37 & -0.59 \\
\hline & & High & 5.04 & 3.79 & -1.25 & 4.46 & 3.14 & -1.32 \\
\hline
\end{tabular}


high levels of felt gender compatibility and egalitarian attitudes toward math ( 0.00 on math self-concept and -0.22 on physics self-concept), and high among students with high levels of felt gender compatibility and traditional attitudes toward math $(-1.25$ on math self-concept and -1.32 on physics self-concept).

\section{DISCUSSION}

Our study discovered and highlights a complex relationship between gender-identity-cum-stereotype patterns and self-concepts in math and physics. Based on prior research $[17,50]$, we know this relationship is likely to have strong impacts on gender differentials in students' identification with math and physics. Our study validates math selfconcept and physics self-concept as distinct measures of academic self-concept and that they may be used to explain gender differences in ability beliefs.

\section{A. Gender identity-cum-stereotype patterns and self-concept}

In accordance with the tendency for cognitive balance, it would be expected that males with strong gender identity would be more likely to internalize math-gender stereotypes, which in turn would influence their level of identification with math and physics or, alternatively, males with strong gender identity and a given level of selfidentification with math and physics are more likely to generalize or project their personal identifications with math on to others of their own gender (math-gender stereotypes). We found that males in our study affirmed stronger gender identity than the females (Table I). Furthermore, males' gender identity played a prominent role in advancing the males' stereotypical attitudes toward math and in self-regulation of their positive self-concept. We found that gender contentedness associated positively and significantly with males' self-concept in math and males' endorsement of math-gender stereotypes associated positively and significantly with their self-concept in physics. These main effects of gender typicality, gender contentedness, and endorsement of math-gender stereotypes on math and physics self-concepts were not significant for the females. This may be explained by research on socialization process that has consistently found that effects of stereotypes differ for males versus females [57]. Accordingly, it has been found that males typically expect to be more successful than females in domains perceived to be suitable for males (math, physics, computer technology, sports) [57,67]. Our findings support the hypothesized positive relationship between felt gender compatibility for males and their self-concept in male-typed domains.

When we examined the combined influence of gender identity and stereotypical attitudes on self-concepts in math and physics, we found that sex parity in self-concept was good among those with high gender typicality and high gender contentedness and low endorsement of math-gender stereotypes. Sex parity in self-concept was low among those with high gender typicality and high gender contentedness and high endorsement of math-gender stereotypes. Our findings suggest that high endorsement of stereotypical attitudes triggers a self-limiting pressure from a need to conform to gender expectations, which has a negative impact on females' evaluation of self in math and physics. This is especially true when high gender typicality and stereotypical beliefs are combined with low gender contentedness (see Tables III and IV and Fig. 2).

We found that identification as gender typical and satisfaction with gender assignment did not associate negatively with females' self-concept in math or physics. In fact, females with high gender contentedness reported slightly higher self-concept in math and significantly higher self-concept in physics than females with lower gender contentedness (for math self-concept, mean values were 4.36 and 4.00 , respectively, $p>0.05$, and for physics selfconcept, mean values were 3.46 and 2.98 , respectively, $F=4.24, p<0.05$ ) (see Table II). Egan and Perry [18] note that in contexts with greater social pressure for children to conform to gender-role norms, gender contentedness is even more important in sustaining self-esteem and perceived social competence. They suggest that children who are not content with their gender assignment and perceive a lot of pressure to conform to gender stereotypes experience lower self-esteem. Our findings clearly indicate the value of positive gender identity in relation to math and physics identities and suggest that femininity is not necessarily harmful to females when associated with maletyped knowledge domains.

\section{B. Implications for science education}

Self-concept in the quantitative domains is considered to be a strong predictor of STEM related educational and occupational choices and retention of students in STEM fields $[28,68]$. Enhancement of self-concept in the quantitative domains is the widespread goal of math and science education reform efforts aimed at reducing gender inequities in STEM fields. Results of our confirmatory factor analysis indicated that math self-concept and physics self-concept are distinct constructs. This distinction is important because most discussions of academic selfconcept have focused on the contrast between quantitative domains (often "math self-concept") versus verbal domains (often "language self-concept") or between general academic self-concept versus subject-specific (math, science, or language) self-concept $[26,62,68,69]$.

Hazari et al. [49] examined the physics identities in a sample of college students in the United States by investigating its relationship with academic background, interest, and past school science experiences. The researchers found that there was no effect on the physics identities of the students through instructional interventions such as 
female science role models, collaborated group work, and discussions of the lives of female scientists. The researchers concluded that explicit discussion of under-representation of women in science was the only instructional strategy that had a uniquely strong positive impact on female students' physics identity but had no impact for male students. Their study was not designed to investigate why explicit discussion of underrepresentation issues and gender biases influence changes in females' self-perceptions with respect to physics. Our findings on the interactions between females' gender identity and stereotypical attitudes on math and physics self-concept suggest that the reduction of gender biases and stereotype threat will enhance math and physics identities for females. Teacher interventions related to that goal might include the promotion of "growth mindset" rather than "fixed mindset" [70] and explicit discussions in the classroom regarding stereotypical beliefs and their effects [71].

Our study has a number of limitations. First, the survey design relies on a self-report method of data collection, and descriptive, not explanatory, methodology. The findings, therefore, do not establish cause-and-effect relationships between felt gender compatibility, math-gender stereotypes, and self-concepts in math and physics. Second, the study assessed only explicitly endorsed math-gender stereotypes, whereas recent research in the U.S. on social identity threat suggests that a stereotype need not be explicitly endorsed to influence individual behavior, and a lack of explicit endorsement does not imply a lack of influence [72,73]. This study was not designed to capture the effects of what have been called "implicit stereotypes" [72]. Third, survey methodology is vulnerable to measurement bias. Asking respondents if they are a "good example" of their assigned gender group or if they feel they are "satisfied" and "happy" with their gender assignment is a cognitive evaluation of the importance of gender in an individual's conceptions of self. The importance assigned to gender does not necessarily mean its salience, the probability that gender will influence behavior in math and science classrooms. Our findings also didn't take into consideration the potential influence of national culture. For example, is it possible that gender typicality is more likely to be associated with negative outcomes in cultures with more rigid norms? As noted by Patterson [74], more research is needed to assess the cross-cultural aspects of self-concept but caution should be exercised in extending findings from one cultural context to the other (p. 423).

\section{CONCLUSION}

Self-concept is an important educational outcome $[62,63,68]$. The relationship between gender identity and self-concept in the quantitative domains has been a consistent topic of interest for science educators $[3,11,20,22,49]$. This study in Thailand found that the relationships between felt gender compatibility and self-concepts in math and physics is moderated by sex and level of endorsement of stereotypical attitudes. Various combinations of stereotypical beliefs about math and felt gender compatibility were associated with high or low gender differentials in math and physics self-concepts, which clarify that personal identity-cum-stereotypes patterns play an important role in the way students, especially females, perceive their abilities and develop math and physics identities in accordance with those perceptions.

\section{ACKNOWLEDGMENTS}

We are grateful to Barbara E. Coon and the reviewers of PRST-PER for their critical feedback. No funding source was used to support this work.
[1] N. Betz and G. Hackett, The relationship of mathematics self-efficacy expectations to the selection of science-based college majors, J. Vocat. Behav. 23, 329 (1983).

[2] N. W. Brickhouse and J. T. Potter, Young women's scientific identity formation in an urban context, J. Res. Sci. Teach. 38, 965 (2001).

[3] T. Lerdpornkulrat, R. Koul, and C. Sujivorakul, The influence of ability beliefs and motivational orientation on the self-efficacy of high school science students in Thailand, Aust. J. Educ. 56, 163 (2012).

[4] D. P. Baker and D. P. Jones, Creating gender equality: Cross-national gender stratification and mathematical performance, Sociol. Educ. 66, 91 (1993).
[5] A. Bandura, Social Foundations of Thought and Action: A Social Cognitive Theory (Prentice-Hall, Englewood Cliffs, NJ, 1986).

[6] S. J. Correll, Gender and the career choice process: The role of biases self-assessments, Am. J. Sociology 106, 1691 (2001).

[7] J. S. Eccles, A. Wigfield, R. Harold, and P. B. Blumenfeld, Age and gender differences in children's self- and task perceptions during elementary school, Child Development 64, 830 (1993).

[8] N. M. Else-Quest, J. S. Hyde, and M. C. Linn, Crossnational patterns of gender differences in mathematics: A meta-analysis, Psychol. Bull. 136, 103 (2010). 
[9] D. G. Perry and R. E. Pauletti, Gender and adolescent development, J. Res. Adolesc. 21, 61 (2011).

[10] R. Subrahmanian, Gender equality in education: Definitions and measurements, Int. J. Educ. Dev. 25, 395 (2005).

[11] M. V. Boe and E. K. Henriksen, Love it or leave it: Norwegian students' motivations and expectations for postcompulsory physics, Sci. Educ. 97, 550 (2013).

[12] Office of the Higher Education Commission, Thailand Education Statistics (in Thai) (2013). Retrieved October 13, 2013, from http://www.info.mua.go.th/information/ show_all_statdata_table.php?data_show $=2$.

[13] R. Koul, T. Lerdpornkulrat, and S. Chantara, Relationship between career aspirations and measures of motivation toward biology and physics, and the influence of gender, J. Sci. Educ. Technol. 20, 761 (2011)

[14] S. J. Schwartz, K. Luyckx, and V. L. Vignoles, Handbook of Identity Theory and Research (Springer, New York, 2011).

[15] J. Brotman and F. Moore, Girls and science: A review of four themes in the science education literature, J. Res. Sci. Teach. 45, 971 (2008).

[16] H. B. Carlone and A. Johnson, Understanding the science experiences of successful women of color: Science identity as an analytic lens, J. Res. Sci. Teach. 44, 1187 (2007).

[17] D. Cvencek, A. N. Meltzoff, and A. G. Greenwald, Mathgender stereotypes in elementary school children, Child Dev. 82, 766 (2011).

[18] S. K. Egan and D. G. Perry, Gender identity: A multidimensional analysis with implications for psychosocial adjustment, Dev. Psychol. 37, 451 (2001).

[19] K. Bussey and A. Bandura, Social cognitive theory of gender development and differentiation, Psychol. Rev. 106, 676 (1999).

[20] P. Haussler and L. Hoffmann, A curricular frame for physics education: Development, comparison with students' interests, and impact on students' achievement and self-concept, Sci. Educ. 84, 689 (2000).

[21] U. Kessels, Fitting into the stereotype: How genderstereotyped perceptions of prototypic peers relate to liking for school subjects, Eur. J. Psychol. Educ. 20, 309 (2005).

[22] S. Skaalvik and E. M. Skaalvik, Gender differences in math and verbal self-concept, performance expectations, and motivation, Sex Roles 50, 241 (2004).

[23] A. K. Arens, A. S. Yeung, R. G. Craven, and M. Hasselhorn, The twofold multidimensionality of academic self-concept: Domain specificity and separation between competence and affect components, J. Educ. Psychol. 103, 970 (2011).

[24] J. A. Fredricks and J. S. Eccles, Children's competence and value beliefs from childhood through adolescence: Growth trajectories in two male-sex-typed domains, Dev. Psychol. 38, 519 (2002).

[25] H. W. Marsh, U. Trautwein, O. Lüdtke, O. Köller, and J. Baumert, Academic self-concept, interest, grades, and standardized test scores: Reciprocal effects models of causal ordering, Child Dev. 76, 397 (2005).

[26] R. J. Shavelson, J. J. Hubner, and G. C. Stanton, Selfconcept: Validation of construct interpretations, Rev. Educ. Res. 46, 407 (1976).
[27] H. W. Marsh and A. S. Yeung, Longitudinal structural equation models of academic self-concept and achievement: Gender differences in the development of math and English constructs, Am. Educ. Res. J. 35, 705 (1998).

[28] G. Nagy, H. M. Watt, J. S. Eccles, U. Trautwein, O. Lüdtke, and J. Baumert, The development of students' mathematics self-concept in relation to gender: Different countries, different trajectories?, J. Res. Adolesc. 20, 482 (2010).

[29] L. B. Krogh and P. V. Thomsen, Studying students' attitudes towards science from a cultural perspective but with a quantitative methodology: Border crossing into the physics classroom., Int. J. Sci. Educ. 27, 281 (2005).

[30] P. Murphy and E. Whitelegg, Girls in the Physics Classroom: A Review of the Research on the Participation of Girls in Physics (Institute of Physics, London, 2006).

[31] P. Murphy and E. Whitelegg, Girls and physics: Continuing barriers to 'belonging', Curric. J. 17, 281 (2006).

[32] M. Sáinz and J. Eccles, Self-concept of computer and math ability: Gender implications across time and within ICT studies, J. Vocat. Behav. 80, 486 (2012).

[33] H. B. Carlone, The cultural production of science in reform-based physics: Girls' access, participation, and resistance, J. Res. Sci. Teach. 41, 392 (2004).

[34] D. Baker, The influence of role-specific self- concept and sex-role identity on career choices in science, J. Res. Sci. Teach. 24, 739 (1987).

[35] J. Gilbert and S. Calvert, Challenging accepted wisdom: Looking at the gender and science education question through a different lens, Int. J. Sci. Educ. 25, 861 (2003).

[36] A. T. Danielsson, Exploring woman university physics students "Doing Gender" and "Doing Physics", Gender Educ. 24, 25 (2012).

[37] E. V. Howes, Connecting girls and science: Constructivism, feminism, and science education reform (Teachers College Press, New York, 2002).

[38] L. Kohlberg, A cognitive-developmental analysis of children's sex-role concepts and attitudes, in The Development of Sex Differences, edited by E. E. Maccody (Stanford University Press, Stanford, CA, 1966), pp. 82-173.

[39] K. Drury, W. M. Bukowski, A. M. Velasquez, and L. StellaLopez, Victimization and gender identity in single-sex and mixed-sex schools: Examining contextual variations in pressure to conform to gender norms, Sex Roles 69, 442 (2013).

[40] W. S. Hall and P. E. Jose, Cultural effects on the development of equality and inequality, in The Child's Construction of Social Inequality, edited by R. L. Leahy (Academic Press, New York, 1983), pp. 253-285.

[41] K. Deaux and M. LaFrance, Gender, in Handbook of Social Psychology, edited by D. T. Gilbert, S. T. Fiske, and G. Lindzey (McGraw-Hill, Boston, 1998), pp. 788-827.

[42] T. L. Ruble, R. Cohen, and D. N. Ruble, Sex stereotypes: Occupational barriers for women, Am. Behav. Sci. 27, 339 (1984).

[43] L. Archer, J. DeWitt, J. Osborne, J. Dillon, B. Willis, and B. Wong, 'Not girly, not sexy, not glamorous': Primary school girls' and parents' constructions of science aspirations, Pedagog. Cult. Soc. 21, 171 (2013). 
[44] B. A. Nosek, M. R. Banaji, and A. G. Greenwald, Math $=$ maleme $=$ female, therefore math $\neq$ me, J. Pers. Soc. Psychol. 83, 44 (2002).

[45] D. D. Tobin, M. Menon, M. Menon, B. C. Spatta, E. V. E. Hodges, and D. G. Perry, The intrapsychics of gender: A model of self-socialization, Psychol. Rev. 117, 601 (2010).

[46] S. J. Correll, Constraints into preferences: Gender, status, and emerging career aspirations, Am. Sociol. Rev. 69, 93 (2004).

[47] A. Bandura, Social Learning Theory (Prentice-Hall, Englewood Cliffs, NJ, 1977).

[48] C. D. Evans and A. B. Diekman, On motivated role selection: Gender beliefs, distant goals, and career interest, Psychol. Women Q. 33, 235 (2009).

[49] Z. Hazari, G. Sonnert, P. M. Sadler, and M.-C. Shanahan, Connecting high school physics experiences, outcome expectations, physics identity, and physics career choice: A gender study, J. Res. Sci. Teach. 47, 978 (2010).

[50] A. G. Greenwald, M. R. Banaji, L. A. Rudman, S. D. Farnham, B. A. Nosek, and D. S. Mellott, A unified theory of implicit attitudes, stereotypes, self-esteem, and selfconcept, Psychol. Rev. 109, 3 (2002).

[51] F. Heider, Attitudes and cognitive organization, J. Psychol. Interdiscipl. Appl. 21, 107 (1946).

[52] V. Sawtell, E. Brewe, and L. H. Kramer, Exploring the relationship between self-efficacy and retention in introductory physics, J. Res. Sci. Teach. 49, 1096 (2012).

[53] L. S. Liben and R. S. Bigler, The developmental course of gender differentiation: Conceptualizing, measuring, and evaluating constructs and pathways, Monographs of the Society for Research in Child Development 67, 1 (2002).

[54] P. R. Carver, J. L. Yunger, and D. G. Perry, Gender identity and adjustment in middle childhood, Sex Roles 49, 95 (2003).

[55] B. Gentile, S. Grabe, B. Dolan-Pascoe, J. M. Twenge, B. E. Wells, and A. Maitino, Gender differences in domainspecific self-esteem: A meta-analysis, Rev. Gen. Psychol. 13, 34 (2009).

[56] C. Leaper and S. R. Van, Masculinity ideology, covert sexism, and perceived gender typicality in relation to young men's academic motivation and choices in college, Psychol. Men. Masc. 9, 139 (2008).

[57] B. Kurtz-Costes, S. J. Rowley, A. Harris-Britt, and T. A. Woods, Gender stereotypes about mathematics and science and self-perceptions of ability in late childhood and early adolescence, Merrill Palmer Quart. 54, 386 (2008).

[58] O. Behling and A. K. Law, Translating Questionnaires and Other Research Instruments: Problems and Solutions (Sage, Thousand Oaks, CA, 2000).

[59] H. W. Marsh, The content specificity of relations between academic achievement and academic self-concept, J. Educ. Psychol. 84, 35 (1992).

[60] J. Pietsch, R. Walker, and E. Chapman, The relationship among self-concept, self-efficacy, and performance in mathematics during secondary school, J. Educ. Psychol. 95, 589 (2003).

[61] P. R. Rosenbaum and D. B. Rubin, The central role of the propensity score in observational studies for causal effects, Biometrika 70, 41 (1983).

[62] H. W. Marsh and R. G. Craven, A reciprocal effects model of the causal ordering of self-concept and achievement: New support for the benefits of enhancing self-concept, in New Frontiers for Self Research, edited by H. W. Marsh, R. G. Craven, and D. McInerney (Information Age Publishing, Greenwich CT, 2005), Vol. 2, pp. 17-51.

[63] F. Preckel, T. Goetz, R. Pekrun, and M. Kleine, Gender differences in gifted and average-ability students: Comparing girls' and boys' achievement, self-concept, interest, and motivation in mathematics, Gifted Child Quart. 52, 146 (2008).

[64] G. Crombie, N. Sinclair, N. Silverthorn, B. M. Byrne, D. L. DuBios, and A. Trinneer, Predictors of young adolescents' math grades and course enrollment intentions: Gender similarities and differences, Sex Roles 52, 351 (2005).

[65] S. L. Hanson, M. Schaub, and D. P. Baker, Gender stratification in the science pipeline: A comparative analysis of seven countries, Gender Soc. 10, 271 (1996).

[66] J. Cohen, Quantitative methods in psychology: A power primer, Psychol. Bull. 112, 155 (1992).

[67] D. Martinot and M. Désert, Awareness of gender stereotype, personal beliefs and self-perceptions regarding math ability: When boys do not surpass girls, Soc. Psychol. Educ. 10, 455 (2007).

[68] A. J. O’Mara, H. W. Marsh, R. G. Craven, and R. L. Debus, Do self-concept interventions make a difference? A synergistic blend of construct validation and meta-analysis, Educ. Psychol. 41, 181 (2006).

[69] H. W. Marsh, Students' evaluations of university teaching: Research findings, methodological issues, and directions for future research, Int. J. Educ. Res. 11, 253 (1987).

[70] C. S. Dweck, Mindset: The New Psychology of Success (Random House, New York, 2006).

[71] N. Ambady, S. K. Paik, J. Steele, A. Owen-Smith, and J. P. Mitchell, Deflecting negative self-relevant stereotype activation: The effects of individuation, J. Exp. Soc. Psychol. 40, 401 (2004).

[72] A. K. Kiefer and D. Sekaquaptewa, Implicit stereotypes, gender identification, and math-related outcomes: A prospective study of female college students, Psychol. Sci. 18, 13 (2007).

[73] B. A. Nosek, F. L. Smyth, N. Sriram, N. M. Lindner, T. Devos, A. Ayala et al., National differences in genderscience stereotypes predict national sex differences in science and math achievement., Proc. Natl. Acad. Sci. U.S.A. 106, 10593 (2009).

[74] M. Patterson, Self-perceived gender typicality, gendertyped attributes, and gender stereotype endorsement in elementary-school-aged children, Sex Roles 67, 422 (2012). 